\title{
Fighting COVID-19 in Iran; Economic Challenges Ahead
}

\author{
Atefeh Zandifar, MD'; Rahim Badrfam, $\mathrm{MD}^{2 *}$ \\ 'Social Determinants of Health Research Center (SDH), Alborz University of Medical Sciences, Karaj, Iran \\ ${ }^{2}$ Roozbeh Hospital, Tehran University of Medical Sciences, Tehran, Iran
}

$\mathrm{L}$ ess than two months after the detection and spread of COVID-19 in Wuhan, China, the disease has spread to other countries. As of March 9, more than 100,000 people around the world have been infected with the disease and unfortunately, about 3800 people have died. However, this situation may continue for an indefinite period of time. In Iran, following the identification and announcement of the first cases of the disease on February 20, the status of becoming infected and dying from COVID-19 has been on the rise. In spite of all the efforts of various medical groups managed by the Ministry of Health of the Islamic Republic of Iran, during the last 19 days (until this writing), we have witnessed nearly 6600 cases of infection and nearly 200 deaths.

The Director General of the World Health Organization (WHO) emphasizes the need for a comprehensive global response to the disease and the need for more serious steps taken by all governments in addition to the health and medical sectors, including political and diplomatic sectors, finance, trade, transport and others. He also warns all countries that the WHO is concerned about the spread of the disease to countries with poor health systems and with more economic bottlenecks. ${ }^{2}$

The Islamic Republic of Iran, due to its serious and continuous struggle against this global problem, has taken the necessary measures to deal with this disease before and after its spread to Iran. Iran's performance in mobilizing government facilities and community and civil society was considered a fair and rational approach as assessed by WHO representatives. They also stated that they were impressed by the knowledge and commitment of the Iranian medical staff. ${ }^{3}$ Despite recent economic problems in Iran, according to the WHO report, Iran has performed well in implementing health programs nationwide, and may even serve as a model for other countries. ${ }^{4}$ The most important reasons for this success can be attributed to the efforts and endurance of the Iranian people and their high level of social capital. ${ }^{5-6}$ This is Iran's strength in the fight against COVID-19.7

The way to fight COVOID-19 seems to be a tough one.
In addition to the need for trust and solidarity, proper and sustainable economic resources and using them right use are needed. Given the limitations of available resources and the challenges ahead, managing these resources requires the administration's diligence and effort to maximize the profitability of existing resources.

Given the vast scope of work, the need to pay attention to the experiences of other countries and to assist international organizations with global experience in this field, such as the WHO, seems reasonable. Of course, it seems that these conditions are well under way.

Throughout history, the Iranian people have always gone through difficult paths with endurance, and will likely win this new fight, as well.

\section{Authors' Contribution}

All authors contributed equally to literature search, writing manuscript, etc.

\section{Conflict of Interest Disclosures}

None.

\section{Ethical Statement}

Not applicable.

\section{References}

1. World Health Organization. Situational Report-9 March, 2020. Available from: https://www.who.int/docs/default-source/ coronaviruse/situation-reports/20200309-sitrep-49-covid-19. pdf?sfvrsn=70dabe61_2. 2020.

2. World Health Organization, speeches, 5 March, 2020. Available from: https://www.who.int/dg/speeches/detail/who-directorgeneral-s-opening-remarks-at-the-media-briefing-on-covid-19---5march-2020.

3. Ministry of Foreign Affairs (Iran), newsview, 5 March, 2020. Available from: https://en.mfa.ir/portal/newsview/577179/who-praises-roleof-iranian-religious-leaders-in-fight-against-coronavirus. 2020.

4. World Health Organization,IRIS Home-2018. Available from: URL: https://apps.who.int/iris/handle/10665/326243. 2018

5. Badrfam R, Zandifar A. Attention to Social Capital In Iran After Recent Flood. J Iranian Med Council. 2019;1(3):151.

6. Mohammadi MR, Khaleghi A, Badrfam R, Alavi SS, Zandifar A Ahmadi A, et al. Social capital in general population of Tehran province in comparison with other provinces of Iran. Journal of Iranian Medical Council. 2019;1(3):124-32.

7. Zandifar A. BR. Iranian mental health during the COVID-19 epidemic. Asian J Psychiatr. 2020;51:101990. doi: 10.1016/j. ajp.2020.101990. 